\title{
Research on Shoppers' Psychology and Behavior in Public Space of the Commercial Building
}

\author{
Gong Wendi ${ }^{1}$, Zheng Yan $^{2}$ \\ ${ }^{1}$ School of Architecture, South China University of Technology, Guangzhou, China \\ ${ }^{2}$ Environmental Art Design institute, Architecture Design \& Research Institute of South China University of Technology, Guangzhou, China
}

\section{Email address:}

531533367@qq.com (Gong Wendi), hg13609014774@163.com (Zheng Yan)

\section{To cite this article:}

Gong Wendi, Zheng Yan. Research on Shoppers' Psychology and Behavior in Public Space of the Commercial Building. Science Discovery. Vol. 8, No. 6, 2020, pp. 146-151. doi: 10.11648/j.sd.20200806.15

Received: November 24, 2020; Accepted: December 16, 2020; Published: January 12, 2021

\begin{abstract}
In the context of continuous innovation in global business formats, our country's commercial architectural design is always exploring and moving forward at the same time. In this paper, large commercial buildings in Guangzhou and Hong Kong will be selected as research Subjects. The psychological and behavioral patterns of shoppers in the public spaces of these commercial buildings will also be analyzed and studied, which mainly through reading literature and going to the site, and also including questionnaire method. In this process, the psychological needs of shoppers for public space in large commercial buildings will be investigated, along with the behavioral effects of different modes of public space in large commercial buildings on shoppers. To sum up, it is to study the interaction between the psychology and behavior of shoppers and the public space of commercial buildings. Through the conclusion, it is found that the environment and people are always in a complementary relationship, and human psychology and behavior should be the starting point and destination of environmental design. It is hoped that the environment design and human psychology and behavior are studied as a more direct relationship, so as to bring some inspiration to the design of public space in large commercial buildings.
\end{abstract}

Keywords: Commercial Architecture, Public Space, Shopper's Psychology and Behavior

\section{大型商业建筑公共空间购物者心理与行为模式研究}

宫闻笛 ${ }^{1}$, 郑炎 ${ }^{2}$

1华南理工大学建筑学院, 广州, 中国

2环境艺术一所, 华南理工大学建筑设计研究院有限公司, 广州, 中国

邮箱

531533367@qq.com（宫闻笛），hg13609014774@163.com（郑炎）

摘要：在全球化商业业态不断创新的背景下，我国商业建筑设计也在不断探索中前进，本文将选取广州与香港大型商 业建筑作为研究载体, 对其公共空间中购物者心理与行为模式进行分析研究, 主要通过文献查阅法、实地调查法来总 结归纳购物者对大型商业建筑公共空间的心理需求以及大型商业建筑不同公共空间模式对购物者的行为影响。通过总 结发现环境与人始终处于相辅相成的关系, 人的心理与行为应成为环境设计的出发点与归宿, 将环境与人的心理行为 作为一种更直接的关系进行研究, 以此希望对大型商业建筑公共空间设计带来一些启发。

关键词: 商业建筑, 公共空间, 购物者心理与行为 


\section{1. 引言}

随着时代的变迁与发展, 社会的经济状况和大众的生 活方式发生了深刻变革, 商业活动在日常生活中扮演着越 来越重的角色。目前国内的商业建筑相关研究中, 早期有 曹杰勇《商业建筑中庭空间设计研究》、张婧《大型商业 建筑公共空间设计研究》针对商业建筑公共空间设计进行 较为综合全面的总结概括, 但由于事物的更新换代, 具有 一定时效性的问题; 陈姗姗的《购物中心公共体验性设计 研究》则是将体验式设计作为主要研究内容, 提出相关设 计原则与方法, 体验式设计即是开始注重购物者的心理感 受; 后有王强《大型购物中心内部步行街公共空间设计探 究》、刘婷《购物中心中庭空间设计研究》在公共空间中 再划分出某一类空间进行探究; 还有将研究范围扩展至室 外公共空间。而开始将空间设计结合使用者行为心理分析 的研究早期有徐从淮《行为空间论》, 以多个学科为理论 基础从多方位深入剖析人的行为对空间环境的需求。后有 武扬《购物者心理与行为在商业建筑设计中的体现》开始 在商业建筑中访问探索购物者的心理行为, 后面也开始陆 续出现基于行为心理的商业建筑相关研究, 如李颜 《基于 环境行为与心理分析的购物中心空间模式设计研究》、金 玉杰《基于行为心理的大型商业建筑外部空间环境设计研 究》等。

公共空间是商业建筑中最有活力的空间。怎样的公共 环境、空间、氛围能够更好的吸引人群，让购物者能够获 得良好体验并驻足? 这是随着时代发展会一直存在的命 题。因此本文将对为商业建筑内承担人们休悡、交往、娱 乐等非营利性活动的公共空间进行研究。一般包括边厅、 门厅、走廊等交通空间, 中庭、边庭、室内外广场等体闲 娱乐空间。重点选择港澳与内陆相关商业建筑进行实地调 研分析, 探讨购物者心理及行为与公共空间的相互作用, 从而为未来商业建筑公共空间的设计提供一定参考价值。

\section{2. 商业建筑公共空间发展}

新世纪的到来, 电商的出现与发展对传统商业建筑产 生了巨大的冲击, 因此商业建筑需要及时的改变来适应当 下的时代背景。而其公共空间在适应其变化需求时呈现多 元化的发展趋势。

（1）公共空间功能多元化: 原基本只有休想功能的 公共空间如今还开拓承载了许多其他的活动, 比如表演、 互动、大促销、展览等, 更多的体验从而吸引更多购物者 的眼球, 产生停留的欲望。

（2）公共空间设计开放化：商业建筑公共空间开始 探索空间的不同使用功能, 考虑为人们的社会活动提供空 间场所、丰富的空间感受以及新鲜的感官和心理体验, 同 时商业建筑公共空间开始渗透到城市公共空间, 尤其商业 建筑外部空间是商业活动与城市社会活动的介质空间。[1] 无论从承载功能或围合形式都将呈现出开放式的设计。

（3）公共空间层次复杂化: “内部公共空间的层次包 括形式层次、意向层次和意义层次三种。形式层次是购物 者可以直接感知到的内部公共空间表面的状态:形式、位
置、色彩、小品等特征; 意向层次是指购物者通过内部公 共空间的结构、场所特征等感受到空间的特征和心理变化; 意义层次是指购物者通过内部公共空间所隐藏的文化内 容, 传递主题文化, 引起消费者的归属感和体验性。体验 化设计就是形式、意向和意义层面的统一, 塑造出引起消 费者共鸣的环境。”[2]

\section{3. 购物者所包含的心理与行为特征}

在全球化商业业态不断创新的背景之下, 商业建筑依 然在不断摸索中前进，而想要避免同质化、富有创新的商 业空间设计, 就需要对商业氛围的灵魂一购物者进行详细 的研究。社会心理学家依据对各类购物群体的生活方式、 经常消费的产品及服务、年龄与收入等相关信息, 将购物 者划分为任务购物型、规律购物型、强迫购物型、娱乐购 物型、严谨购物型和冷漠购物型六类群体。现代商业心理 学家更为简洁, 从目的性入手, 将购物者分为无目的性购 物、选择性购物、有目的性的购物这三类。[3]凯文・林奇 把美国人的购物行为描述为“人们在购物时, 时而到各商 店游逛, 时而与熟人聊天, 或者坐着休息、看看周围其他 人的活动, 或者吃些东西、看看喷泉或听听音乐, 以购买 合适的商品为目的, 在寻找一段时间后经过停息、进餐、 娱乐以放松心情、缓解疲劳, 再继续下一步行动。”[4]从 以上总结可以看出不管购物者是否带有目的性的购物, 过 程中都会伴有非消费行为。而这些行为既需要一定的空间 载体, 又需要通过公共空间的设计对购物者进行诱导。非 目的性消费行为、体验式消费时代早已悄悄来临。

\section{4. 购物者对商业建筑公共空间的心理需求}

正如上述段落所提及越来越多的购物者是无目的性 的进行体验游走, 那商业建筑中公共开放空间也显得越来 越重要, 一方面作为商铺区与建筑外部街道间的过渡; 另 一方面可用作丰富吸引人群。设计者需要以分析人们心理 行为为基准, 因此本段先从购物者角度出发, 通过现场调 研总结其对商业建筑公共空间的需求有哪些, 以此来探讨 公共空间设计的发展方向。[5]

\section{1. 人情味需求}

人情味(Humanity), 即以人为本, 充分关注人的身心 体验。设计师注重人们的参与、建筑品质的实现、空间序 列的组织, 而不是仅仅关注建筑商业价值的实现。[6]不管 规模多大的商场或许需要开阔明亮的中庭空间, 或许也不 一定有自然光线的需求, 但终是要回归到人们在这之间最 大的使用舒适度中去衡量。

\subsection{1. 良好的环境}

公共空间的环境质量是其是否人性化的重要考量标 准。如果说界面设计是公共空间的“硬件”设施, 那环境设 计就是其“软件”设施。这些设施同时都是赋予公共空间活 力和聚集人气的重要手段。公共空间的环境主要包含光环 境、色彩环境以及景观、小品几方面。[7]在光环境与色彩 
环境上, 无论采用自然光还是人造光, 都对空间氛围的营造起 着不可估量的作用。香港太古汇东庭采用室内装饰灯光, 灯 具阵列排布倒挂, 使整体氛围更显精致（图1）; 海港城 中庭圆顶采用彩色玻璃窗, 外圈灯带照出暖色光线, 空间 散发出欧式的古典气息（图2）; 香港金融中心则顶部皆 为半透材料, 让自然光充分散入, 购物者在任何一处都能 感受着明亮与轻快（图3）。

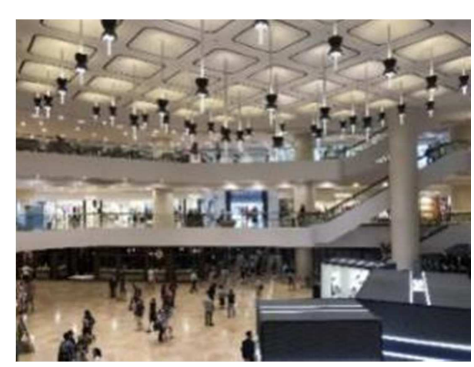

图1 香港太古汇东庭。

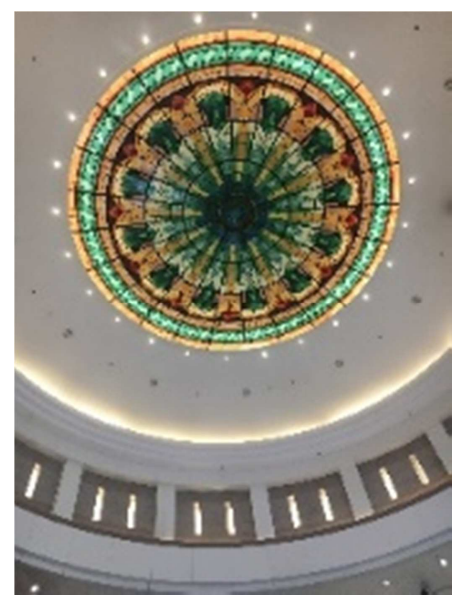

图2 香港海港城。



图3 香港金融中心。

光、色彩环境之后便是景观小品等设施的完善, 有研 究显示多数消费者会在购物中心逗留 2 个小时以上并会产 生疲劳感, 而坐席是购物者认为对疲劳最有帮助的设施, [8]因此必要的设施才会满足顾客的休喤需求并能使顾客 有较长时间的停留, 同时享受购物与交往的乐趣。如果太 过空旷的空间无足够景观小品等基本设施的设置, 会使氛 围变得萧条、让人缺乏亲切感（图4）。而在公共空间中 设置有趣多样的景观装置, 在满足购物者基本需求的同时, 还能促进人们与场地进行良好的互动。[9]（图5)

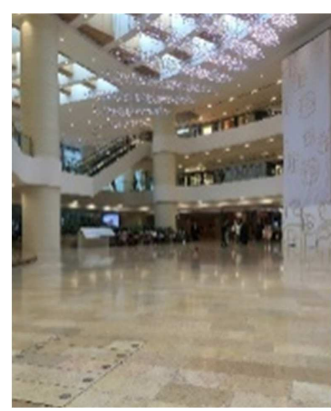

图4 香港太古汇西庭。

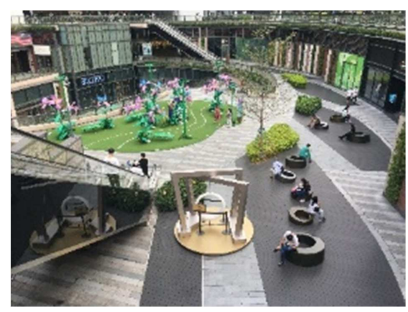

图5 广州天环广场室外中庭。

\subsection{2. 开放与私密}

公共开放性是公共空间最首要的特点, 其使空间内部 相互渗透产生丰富的空间变化。而通过调研会发现在室内、 高差变化、小空间界定上有一定设计的公共区域相比无任 何特别设计、仅简单放置休咊座椅的更容易吸引购物者。 广州 K11在公共空间通过下沉设计围合出了休咊空间, 使 空间有了限定感，进而提高了购物者在使用时的舒适性 （图6）。而在顶层公共空间, 环绕柱子围合了相对私密 的二层小空间, 围合墙面进行一定的人工景观装置, 让人 们再闹市中也能寻求一片静烅（图7）。像类似在商业建 筑中兼容开放与相对私密的公共空间, 不仅让空间的层次 感加强, 也为购物者休憩、交流提供了多样的选择。

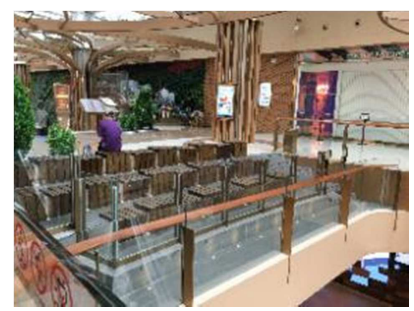

图6 广州K11下沉休熄座椅。

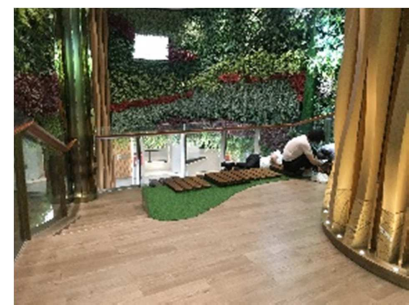

图7 广州K11夹层环柱半私密休鄎空间。

\section{2. 娱乐性需求}

现代属于娱乐业的时代, 人们几乎无法抵抗娱乐带给 我们的诱惑。因此娱乐活动丰富的购物中心往往也能够吸 
引各种类型的消费人群, 并且让公共空间氛围更加活跃, 很好的避免空旷单调的情形。

商业建筑中活动可以是展览、节日庆典、商品促销或 是表演演出, 对于承载这些活动, 公共空间起到了不可小 觑的作用。香港海港城建设虽年代久远, 却经久不衰, 一 直都是香港规模最大的购物中心, 且没有逊色于其他购物 中心。[10]这主要归功于其及时追赶时代的步伐, 并注重 文化的交互体验。例如其集中式的中庭空间放置大型节日 主题艺术装置（图8）、直线形的公共交通空间介入展板 展览（图9）、海港入口广场联合品牌设置主题景观。这 些都给购物者们单纯的购物过程中带来了娱乐性的满足, 并获得更多的情感体验。

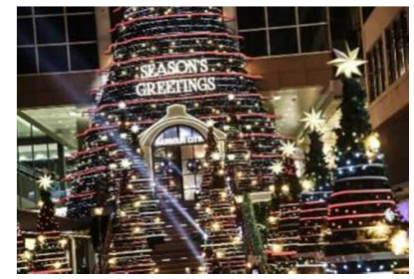

图8 香港海港城圣诞主题。

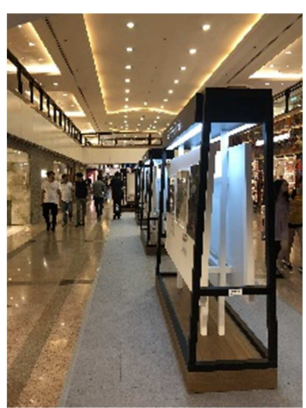

图9 香港海港城展览。

\section{3. 个性化需求}

人类对于“美”的追求从未停止过, 看过千篇一律的风 景, 不一样的风景更会给人带来视觉冲击, 并激发人们的 感官体验和联想。商业建筑公共空间对个性化的着重设计 可以最大限度地吸引消费者的目光, 以满足各类人群追求 独特和个性的心理需求。当代所谓的网红“打卡点”的盛行 很好地诠释了人们对个性设计事物的追求与热衰。

对于商业建筑公共空间的个性化提升总结可从三方 面来展开: 空间界面设计、介入的围合装置设计以及增加 科技感体验。首先, 公共空间的界面大多都是商家的门面 来构成, 因此商家门面的设计会对公共空间的视觉效果有 一定影响。而很多追求个性化的界面以表皮相关设计为首, 目前除了建筑外表皮设计, 室内装饰表皮的视觉效果也受 到越来越多的关注, 其设计不仅局限于比例、结构、材料 等, 更多的是关注购物者最直观的感受和审美倾向, 酷炫、 多元化的表皮可以很好满足人们新奇的视觉体验。[11] 例 如香港太古汇东中庭引入一处咖啡座的内部曲线表皮设 计, 会吸引人不由自主地停驻观赏（图10）。广州正佳广 场首层城市快时尚服装店的过渡空间材料简洁, 但设置具 有一定韵律感的灯光带, 依然创造出强视觉冲击力的空间 效果, 因此又吸引无数购物者前来“打卡”（图11）。

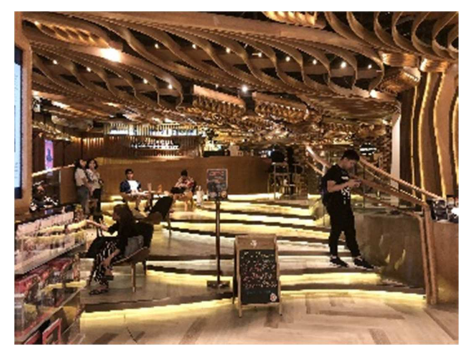

图10 香港海太古汇广场。

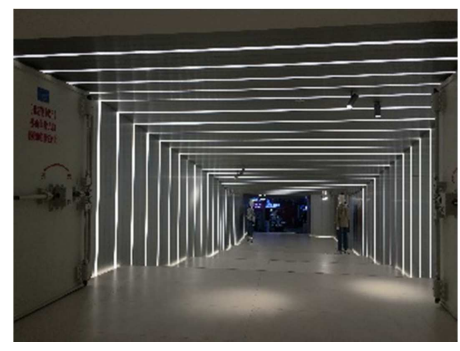

图11 广州正佳广场。

其次，大空间中介入小空间围合装置的做法在各大商场 中庭空间已成常态, 结合不同品牌的促销、饮食或休鄎, 各 自独特个性, 整体让公共空间变得丰富多彩而产生多样有趣 的空间体验。例如香港太古汇东庭中有网格构架结构、实体 金属围合以及开敞汽车主题。（图12）

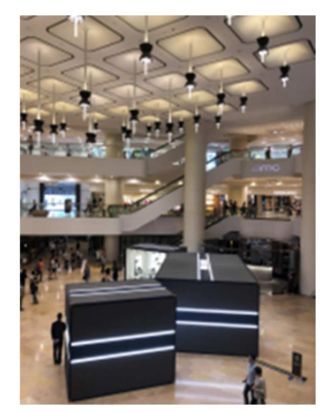

图12 香港太古汇东庭零售点。

最后, 适当增加科技体验感, 科技感强的事物往往带 给人们都会伴有新鲜感。过往, 或许可以通过“软件”设施 的非线性设计来表现其独一无二的特性, 然而现在不仅如 此。响应时代科技的迅猛发展, VR等虚拟技术已逐渐渗 透到我们的生活之中, $\mathrm{VR}$ 游戏设施、移动 $\mathrm{K}$ 歌房、智能 $\mathrm{ai}$ 设备等也随即应运而生。而这些在商业建筑公共空间中的 出现会给购物者们带来难以忘怀的娱乐性体与个性化的 满足。

\section{5. 商业建筑公共空间对购物者行为的影响}

购物者的心理与行为特征与商业建筑公共空间开发 模式是相辅相成的, 两者属于互动关系, 所以下文将从商 业建筑公共空间的不同模式出发, 探讨其对购物者产生的 影响。通过实地建筑调研会发现目前多数大型商业建筑公 共空间无单一模式模式, 多为几种模式组合而成。 
表1 调研商业建筑公共空间汇总表。

\begin{tabular}{|c|c|c|c|}
\hline \multirow{2}{*}{ 商业建筑 } & \multicolumn{3}{|l|}{ 公共空间 } \\
\hline & 平面简图 & 主要模式 & 组合类型 \\
\hline 1. 广州正佳广场 & & 集中式 & 集中发散 \\
\hline 2. 广州天环广场 & & 内街式 & $\begin{array}{l}\text { 点线串联与集 } \\
\text { 中发散结合 }\end{array}$ \\
\hline 3. 广州K11购物中心 & & 内街式 & 主轴副轴交错 \\
\hline 4. 香港海港城 & & 内街式 & 主轴副轴交错 \\
\hline 5. 香港太古汇 & & 内街式 & 点线串联 \\
\hline 6. 香港国际金融中心 & & 内街式 & 点线串联 \\
\hline
\end{tabular}

\section{1. 商业建筑公共空间“集中式”模式}

“集中式”空间模式多表现为以中庭为主, 其他功能环 绕聚拢的模式，相对于“内街式”布局更加紧凑。中庭的类 型可分为纯交通型中庭、纯景观型中庭、休闲活动型中庭。 [12]上述调研中仅广州正佳广场公共空间的主要模式为 “集中式”, 其中庭将三个类型都包含在内, 相对规模较大, 中央中庭为中心焦点, 其他小中庭发散分布串联而成。集 中式中庭会使购物者目光、步伐聚集于此, 具有明确的向 心力和凝聚力, 习惯性围绕中心进行购物, 方向性不强。 [13]（图13、图14）

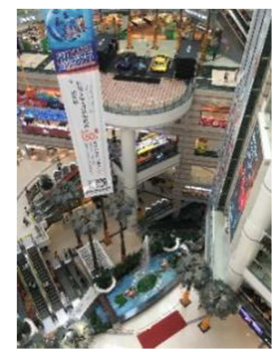

图13 广州正佳广场中庭空间俯视图。



图14 广州正佳广场集中式中庭空间。

\section{2. 商业建筑公共空间“内街式”模式}

“内街式”空间开发模式是指采用一条或几条线性空 间将各类功能空间串联在一起的空间模式。内街式模式一 般具有几点基本特征: 一、垂直界面为连续商业店铺组成。 二、人工光源或天然采光营造室外天空感受。三、空间具 有较长的街型行走路线。[14]同时为使购物者行走其中, 因此“内街模式”空间会有一定韵律与节奏, 往往会设置节 点放大空间, 形成比较丰富的空间形态, 也是目前多数商
业建筑公共空间普遍采用的模式（图15）。“内街式”空间 不同于“集中式”空间，后者更注重停留，而前者是伴随着 流动, 方向性更强, 因此更具有指引性, 可以使购物者在 建筑中有更好的流动性体验。

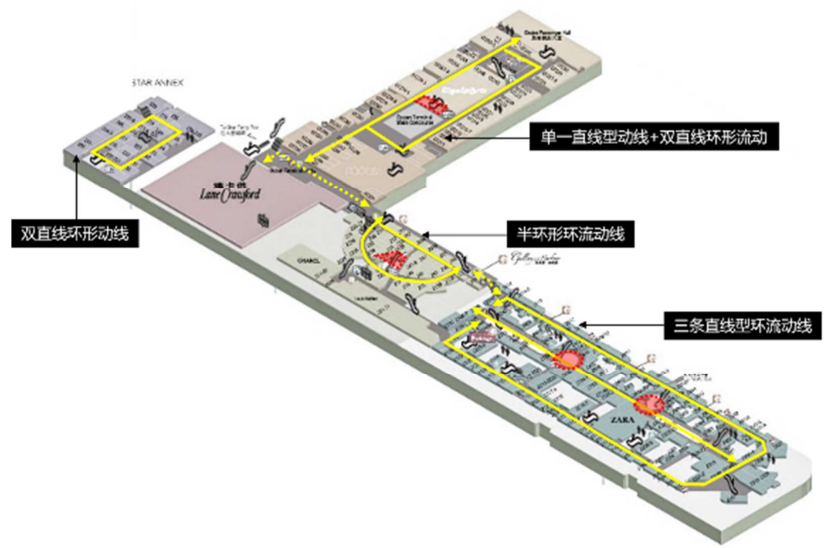

图15 香港海港城平面图流线分析。

\section{6. 结论}

本文从商业建筑公共空间发展与购物者的心理行为 特点出发延伸至购物者对商业建筑公共空间的心理需求, 最后再反向分析商业建筑公共空间存在的模式可能对购 物者的行为带来哪些影响。

讨论环境与人们行为的关系，应从两者的关系入手， 而环境与人的关系表现为: 人们对环境的需求和环境被人 们所感知。环境与人的行为是相辅相成的关系, 环境可以 对人们的行为产生促进或是阻碍作用。把环境与人的行为 作为一种更直接的关系进行研究, 对建筑设计与环境设计 都有着深远的意义。[15]人的心理与行为应成为环境设计 的出发点与归宿。总结已有经验是为了更好的实践, 希望 未来商业建筑设计会有更多的可能性以带给购物者们更 好的体验。

\section{参考文献}

[1] 金玉洁, 基于行为心理的大型商业建筑外部空间环境设计 研究[D].河北工程大学, 2010.05。

[2] 王玮.大型商业建筑空间设计影响因素及发展趋势[J].低温 建筑技术，2011年第9期：15-16。

[3] 武扬.购物者心理与行为在商业建筑设计中的体现 [J].建筑 学报, 200701：72-76。

[4] 凯文林奇. 《城市意向》 [M]. 方益萍何晓军译, 华夏出版社, 2001年04月。

[5] 林康, 行为心理的建筑空间设计研究 [J]. 规划与设计, 2018.11：68。

[6] 徐从淮, 行为空间论[D].天津大学, 2005.08: 75。 
[7] 张婧, 大型商业建筑公共空间设计研究 [D].同济大学, 2007.03: 62。

[8] 郭吴栩, 基于环境行为与心理分析的购物中心空间模式设 计研究[D].华南理工大学, 2014.06。

[9] 吴琪, 商业户外公共空间体验式景观研究 [J]. 美与时代, 202006: 83-84。

[10] 在香港,商业也许有一百种受欢迎的方式 [J].泸港经济, 2017.09: 38-40。

[11] 陈姗姗, 购物中心公共空间体验性设计研究[D].华南理工大 学, 2012.06: 61。
[12] 王强, 大型购物中心内部步行街公共空间设计探究[D].深圳 大学，2013.05。

[13] 赵燕, 既有商业建筑内部公共空间整合改造设计研[D].西安 建筑科技大学，2019.06：86。

[14] 靳树春, 商业建筑“内街空间”设计研究[D].西安建筑科技大 学, 2009.06。

[15] 曹杰勇, 商业建筑中庭空间设计研究[D]. 西安建筑科技大学, 2003.06: 18 